\title{
Tax Exemptions of Ethical Products Revisited
}

\author{
Dina Kassab ${ }^{1}$ (D)
}

Accepted: 4 August 2020 / Published online: 14 August 2020

(c) Springer Nature B.V. 2020

\begin{abstract}
Corporate social responsibility (CSR) activities, being viewed as the corporate's provision of a public good, enable tax exemptions in many economies. We examine, in a monopoly setup with heterogeneous consumers, with social image concerns, whether these tax exemptions are justified. When private and public investments are substitutes, tax exemptions ought to be accorded to CSR activities, and an ad valorem subsidy is welfare superior to a specific one, only when both consumers' social consciousness and reputational concerns are sufficiently low and/or when the marginal cost on the private good market is sufficiently high. Otherwise, a positive ad valorem tax is welfare improving as it redistributes surplus from the firm to consumers while increasing total welfare in the process. However, when the firm's CSR investment complements the government's provision, tax exemptions appear to be suboptimal relative to a positive tax. Specifically, the relative appeal of specific taxes, compared to ad valorem taxes, increases in consumers' reputational concerns and the value of the optimal tax decreases in their level of altruism.
\end{abstract}

Keywords Corporate social responsibility $\cdot$ Progressive Tax $\cdot$ Consumption norms · Reputation $\cdot$ Ad valorem tax $\cdot$ Specific Tax

\section{Introduction}

Economists have long praised the invisible hand of the market which harnesses consumers' and corporations' pursuit of self-interest to the pursuit of efficiency along with the view that, whenever externalities stand in the way of efficiency, the state corrects market failures and redistributes income and wealth since the distribution generated by markets has no reason to fit society's moral standards. From this perspective, it was only natural to think that the State is the sole provider of public goods as their provision is subject to free-riding problems and hence cannot be left in the hands of individuals. However, governments under influence may fail to optimally correct externalities, or bend to wealthy agents' opposition to redistributive policies. Governments may also fail due to inefficiency, high transaction costs or poor information. So citizens and corporations empower themselves and substitute for elected government. Individual and corporate social responsibility

Dina Kassab

dina.kassab@feps.edu.eg

1 Faculty of Economics and Political Science, Cairo University, Giza, Egypt 
have risen as an alternative response to market and redistributive failures and the movement has gained momentum. The question now is: how to correct social responsibility failures or capitalize on their benefits?

Many public goods are privately provided either through direct contributions by individuals or by firms as part of their marketing or business strategy, what we call Corporate Social Responsibility (CSR hereafter) practices. Formally, CSR is "a concept whereby companies integrate social and environmental concerns in their business operations and in their interaction with their stakeholders on voluntary basis" (European Commission 2001). Provision of public goods using direct contributions has been studied extensively. In contrast, there has been relatively little work on private provision by firms. The general assumption of theoretical research in this area is that individuals choose between consumption of a private good and contributions to a pure public good. Yet individuals increasingly face a third option: consumption of impure public goods that generate private and public goods as a joint product.

For example, instead of purchasing regular coffee, consumers have the option to purchase fair trade coffee, with a price premium, and thereby contribute to raising the living standards of farmers and farm workers and help develop the community through scholarship programs, healthcare services and quality improvement training. Thus consumers of fair trade purchase a joint product-coffee consumption and community development. The growing market for premium-priced products which are linked to social causes exemplify this idea. This is the case of cause-related marketing ${ }^{1}$ and lump-sum corporate donations to or expenditures on worthy causes or green activities, which implicitly link the contribution to sales of the company's products. Thus consumers of such products also purchase a joint product - consumption of the private good and investment in the social cause embraced by the firm. In all these examples, the joint product forms an impure public good, with both private and public characteristics.

CSR activities being viewed as the corporate provision of a public good, it is a common practice in many economies that they enable tax exemptions. For instance, The Chilean government offers a variety of tax credits to corporations for charitable donations, most of which are oriented to support educational activities, such as schools, universities, and vocational institutions. Italy has introduced an ecolabelling scheme that provides the purchaser with a sales tax reduction on the purchase price of green products (Bell 2002). In the U.S, tax exemptions are designed so as to promote the adoption of hybrid-electric vehicles (Diamond 2009). The World Bank identifies those tax incentives as an effective means by which governments can fullfill their role in promoting CSR (Fox et al. 2002). Most recently, during the Covid-19 pandemic, the Ministry of Corporate Affairs in India specified CSR activities that enable tax exemptions. ${ }^{2}$ The list included contributions made to the state disaster management authority to fight against Covid-19 and spending related to preventive healthcare and sanitation, while wages paid to workers even during the lockdown period and contributions made to the Chief Minister's Relief Fund does not qualify as CSR.

The present paper investigates whether these exemptions are justified, given the nature of interdependence between the public good provided by the company and that provided

\footnotetext{
1 The practice of explicitly linking the sale of a company's product to company contributions to worthy causes.

2 "What Covid-19 contributions get qualified as CSR expenditure. Here's the complete list," The Economic Times, Apr. 2020, [online].
} 
through the government. For instance, should the same tax exemptions apply to a firm constructing a school for children in a poor neighbourhood and one that incorporates a number of billable hours for its employees to volunteer in public schools? Should the tax policy distinguish between a company donating to build a hospital for cancer patients and one that donates to paint the walls or provide complementary equipment for a public hospital?

The understanding of CSR has matured among both scholars and practicioners. It is about time the focus of the analysis and debates shifts from the desirability and feasibility of CSR to the regulation of CSR, to get the most out of it. Firms' intervention on the market to correct government failures is sometimes necessary, but so is the government's intervention to correct CSR failures and capitalize on its benefits. In doing so, the regulator ought to draw a clear distinction between the different practices, according to whether they complement or substitute for the government provision of the public good. A priori, companies investing in clean energy resources, reducing carbon footprint or providing access to clean water in deprived areas and those enhancing work conditions for their employees or providing some paid staff time to charitable causes should receive a differential treatment, given the public policy objectives of course. The objective of this study is then three-fold: (i) to model consumers' utility when consumption externalities and reputational concerns are relevant, (ii) to compare the effects of an ad valorem tax vis-à-vis a specific one in a market with CSR, and (iii) to provide guidelines for policy makers to determine the optimal way to intervene on a market with CSR activities.

Our model examines a market consisting of consumers with heterogenous preferences towards CSR in a monopoly market where consumers account for how they are perceived when they make their purchasing decision. All along, we assume that only those who buy a firm's product experience a warm-glow and prestige utility and pay for it. CSR being a public good, non-buyers free ride on the warm glow of buyers to derive a social utility from CSR. A benevolent regulator intervenes on the market by imposing either an ad valorem or a specific tax, the collected tax revenues are then recycled in the form of the government provision of a public good, which can either complement or substitute for the CSR investments of the monopolist. Our main findings can be summarized as follows. First, when private and public investments are substitutes, tax exemptions of CSR activities are justified, and an ad valorem subsidy is welfare superior to a specific one, only when both consumers' social consciousness and reputational concerns are sufficiently low. Second, taxing the product with a public add-on, when consumers are sufficiently altruistic, is welfare improving. Third, the more concerned consumers are about their social image the larger the gains from a specific tax, relative to an ad valorem one.

The paper is organized as follows. The next section provides a literature review. Section 2 introduces the basic model. Section 3 contrasts the effects of an ad valorem versus a specific commodity tax when the good in question has a public add-on. The welfare maximizing taxes are examined in Sect. 4 . Section 5 concludes.

\section{Related Literature}

Our research draws on the confluence of three diverse streams of literature: consumer behavior with social externalities, strategic CSR and market outcomes and finally CSR and regulation.

Consumer Behavior with Social Externalities Classic economic models view consumers as rational individuals concerned solely with their own well-being. While this standard 
analysis undoubtedly has an important role in explaining many aspects of consumer behavior, it does not explain consumers' prosocial attitudes, precisely, why consumers would contribute to a public good in a non-cooperative setting, even though there is an underlying free-rider problem. Andreoni (1990) introduces into the utility of individuals a warm glow component or joy of giving; consumers derive some private benefit from the consumption of the private and public goods, but also from the contribution to the public good itself. This altruistic motive behind prosocial behavior is a form socially directed preferences as opposed to the socially embedded preferences, both discussed in Dasgupta et al. (2016). While the former describe the case where individuals have a concern for the welfare of others and hence their consumption decisions take account of the consequences they impose on others, the latter reflect the idea that consumers care about their consumption relative to the average consumption of their peers or a reference group. These models assume that consumers differ in their degree of morality which is their private information and has to be inferred from one's actions. Individuals then use their consumption to signal either their conformity or adherence to a certain group (Bernheim 1994), enhance self-image (Ellingsen and Johannesson 2008) or seek distinction or some reputational payoff (Bénabou and Tirole 2010).

Strategic CSR and market outcomes On the supply side, firms are assumed to be socially responsible because they anticipate a benefit from such a behavior. Our work is related to the strand of theoretical literature that addresses conditions under which firms engage in CSR and its welfare implications [see Crifo and Forget (2015); Kitzmueller and Shimshack (2012)]. This literature found conflicting results regarding CSR in competitive environments. On the one hand, by reducing the market share and the margin on CSR, competition leads to lower levels of CSR (Bagnoli and Watts 2003; Bennett et al. 2013; Branco and Villas-Boas 2015). On the other hand, research also suggests that CSR investments could be a means to escape competition either by signaling quality or through product differentiation (Conrad 2005; Banerjee and Wathieu 2017; Zhou 2018).

Models of vertical product differentiation have been particularly appealing for investigating CSR in imperfectly competitive markets and assessing the impact of regulation on environmental qualtiy and welfare. Typically, in these models, consumers are assumed heterogeneous in their willingness to pay for the green product. Firms decide both on their clean-up effort and welfare is then obtained as the sum of consumer surplus and profits, in addition to the resulting externality, that is the environmental damage. Most of these models then consider the effects of introducing a commodity tax. According to Cremer and Thisse (1994), the choice of a commodity tax rather than an emission tax seems more plausible since emission taxes are not so common as they require more sophisticated information. The idea of the tax essentially is then to reduce product differentiation in order to enhance price competition and increase welfare. The analysis has then been extended to assess the welfare effects of taxes and subsidies (Arora and Gangopadhyay 1995), maximum unit emission standards (Moraga-Gonzalez and Padron-Fumero 2002) and taxation policies that consist in rewarding the green producers and punishing the polluters (Bansal and Gangopadhyay 2003).

CSR and Regulation and the double-dividend hypothesis The Literature on CSR and regulation has evolved along two parallel lines: eco-labeling and green tax policies. The literature on eco-labeling makes the assumption that the social responsibility attribute of a product is a credence good, a market for lemons problem arises and the regulator the regulator intervenes to solve this problem by proposing a certain standard of CSR effort to the firms and providing certification to the firms that comply with the standard (Mitrokostas and Petrakis 2007; Manasakis et al. 2007). Green tax policies, on the other hand are 
regulatory policies that consist in imposing emission taxes on some products and giving subsidies to green products to encourage environmentally responsible production, the public good in question being the reduction of pollution. An interesting idea that emerges from the analysis of environmental taxes is that of the double dividend (Pearce 1991; Goulder 1995; Bovenberg and De Mooij 1994). A green tax reform or a tax swap whereby an ecotax $^{3}$ is levied and the proceeds are devoted to decrease some other distortionary tax while keeping government income constant, may achieve a double dividend, that is (i) an increase in environmental quality, the green dividend and (ii) an increase in welfare from private commodities, the blue dividend (see Freire-González (2018) for a review). The double dividend hypothesis has been tested taking into account the different impacts an environmental tax may have. Most relevant to our analysis is the case where the proceeds of taxation are used to finance a public good such as a public pollution abatement activity (John et al. 1995) and taking into account the heterogeneity in households income, which translates into the degree of regressivity in the environmental tax (Chiroleu-Assouline and Fodha 2014).

Although we do not use a general equilibrium model where the tax proceeds are recycled to reduce some other distortionary tax, our analysis suggests the possibility of a double-dividend occuring from taxing products with a CSR content. The green dividend is then the higher public good that could be achieved through both the CSR investments and the public investment that the tax allows, and, by remote analogy to the double-dividend theory, the additional redistributional benefit that taxing the CSR product enables can be interpreted as the blue dividend. In some cases, taxing CSR products can serve as a means of redistribution by narrowing the pool of green consumers purchasing the good. If altruistic motives are assumed to be correlated with income, the tax payers will then be the consumers at the higher end of the distribution of income who pay larger taxes to make the public good available for all.

\section{Benchmark Model}

In what follows we set up the benchmark model starting from the basic assumptions, and proceeding with the presentation of mechanisms underlying the optimal choice of the producer.

\subsection{Preliminaries and Basic Assumptions}

Consider a monopolist selling a private good at a price $p$ in a market consisting of a continuum of consumers. Alongside the private good production, the monopolist engages in CSR activities to generate a public good. Precisely, for each unit of the private good sold, the firm undertakes a CSR investment of value $s \geq 0$.

Consumers' preferences On the demand side, there is a unit mass of consumers, each indexed by $i$ and having a unit demand $q_{i} \in\{0,1\}$. Consumers have identical preferences regarding the private good denoted by $\alpha>0$. However, owing to variation in education, morality and other personal traits, they are heterogeneous regarding their willingness to pay for the CSR activities that are undertaken by the firm and $\theta_{i} \in[0,1]$ is introduced to

\footnotetext{
3 An eco tax or environmental tax is a positive tax on carbon dioxide emissions.
} 
account for this heterogeneity, with a larger $\theta$ denoting a higher social consciousness. We further assume that the realization of $\theta_{i}$ is private information of consumer $i$, it follows a cumulative distribution $F(\theta)$ and density $f(\theta)$ that are common knowledge.

This set-up creates an opportunity for consumers to signal their type, $\theta$, through the purchase of the green product which we refer to as the reputational benefit, $r(s, p)$. All consumers are assumed to be caring in the terms of (Besley and Ghatak 2007) in the sense that they all care about the overall level of public good available in the economy, $Y$. This particular utility however is independent of their purchase decisions since the weight attributed to each is too small to affect the outcome. Consumer $i$ then derives a utility

$$
u_{i 1}=w_{i}\left(s, \theta_{i}\right)+\mathbb{I}_{s} \gamma r(s, p)+\alpha-p+Y
$$

if he buys the good, and $u_{i 0}=Y$ otherwise; $\gamma>0$ represent the weights attributed to the reputational return from consumption of the green product and $\mathbb{I}_{s}$ is the indicator function that takes the value 1 if $s$ is strictly positive and zero otherwise. Given the public good nature of CSR, non-buyers obtain a free-rider utility which is the public good available. The utility function in (1) captures both forms of motives behind prosocial consumption identified in the literature (see Dasgupta et al. 2016 for a review):

- Socially-directed preferences are reflected in the warm glow utility $w_{i}$ experienced by consumers who finance the CSR investment of the firm by purchasing its product. Specifically, the warm glow utility is given by

$$
w_{i}\left(s, \theta_{i}\right)=\beta s-\frac{1}{2}\left(1-\theta_{i}\right) \mu s^{2}
$$

where $\beta, \mu$ are strictly positive parameters. ${ }^{4}$ All consumers are assumed to be altruistic to some extent as they derive a positive utility from the act of contributing to the public good per se $\left(w_{i}>0, \forall \theta_{i}\right)$. However, consumer $i$ 's ideal level of contribution, at which his warm glow utility is maximized, is $s^{*}\left(\theta_{i}\right)=\frac{\beta}{\left(1-\theta_{i}\right) \mu}$ which increases in $\theta_{i}$. That is, heterogeneity is seen as individuals having different morally ideal efforts that they seek to achieve and self-image value depends on how close their contribution is to that optimal level. ${ }^{5}$ As the amount of contribution increases, the least caring consumers experience a larger decrease in their marginal utility from contributing as for this group the increase in the contribution would be judged exagerated or unnecessary. A similiar assumption is found in the analysis of Alves and Santos-Pinto (2008) and Arora and Gangopadhyay (1995). ${ }^{6}$ Note that $\beta$ and $\mu$ have opposite effects on consumers' willingness to pay for CSR. While a larger $\beta$ increases both the marginal warm glow utility

\footnotetext{
4 The warm glow utility can be generally represented by $w_{i}\left(s, \theta_{i}\right)$ such that $\frac{\partial w_{i}\left(s, \theta_{i}\right)}{\partial s}>0, \frac{\partial^{2} w_{i}\left(s, \theta_{i}\right)}{\partial s^{2}}<0$ and $\frac{\partial^{2} w_{i}\left(s, \theta_{i}\right)}{\partial s \partial \theta_{i}}>0$. However the particular functional form in our model allows an easier analysis of the CSR choice and also captures its effects nicely.

5 This idea is referred to in the literature as the Kantian norm whereby consumers think about what would happen if all others conformed to their own behavior (Daube and Ulph 2016). Alternatively, this could be viewed as consumers all valuing contributions to CSR, however due to differences in income, "affordability" of CSR differs among consumers.

6 Alves and Santos-Pinto (2008) consider the marginal warm glow utility to be non-linearly decreasing in the level of CSR, in their model consumers purchase $q_{i}$ units of the green product and the warm glow component is given by $\theta_{i} s q_{i}-\frac{1}{2}\left(s q_{i}\right)^{2}$. In Arora and Gangopadhyay (1995), utility is given by $s-\frac{p}{\theta_{i}}$ which is decreasing non-linearly in $\theta$.
} 
and that level for each consumer, a larger $\mu$ reduces the morally ideal contributions and also causes a sharper decline in the utility beyond the ideal level. Hence, $\beta$ and $\mu$ will be said to represent the social concern of consumers and their degree of commitment to their morally ideal efforts respectively.

- The reputational benefit from buying the green product, $r(s, p)$, accounts for the socially-embedded preferences. This component of the utility captures the effect of social norms on prosocial behavior (Bénabou and Tirole 2010). Consumers care about the opinion others have of them and derive a positive utility from being seen as giving. In our setup, the degree of altruism of the different consumers being à priori unknown, purchase of the ethical product could serve as a signaling device. This idea is consistent with the empirical findings of the literature (Croson and Treich 2014). ${ }^{7}$ The social prestige from belonging to the group of responsible consumers emerges endogenously as it will be determined by the characteristics of this particular group at equilibrium. It is defined as the difference between the expected value of the social consciousness of the group of responsible consumers and the average social consciousness in the economy, that is,

$$
r(s, p)=E\left(\theta_{i} \mid q_{i}=1\right)-E\left(\theta_{i}\right)
$$

The incremental utility from buying the firm's product over not buying is then

$$
\Delta u_{i}=u_{i 1}-u_{i 0}=\left(\beta s-\frac{1}{2}\left(1-\theta_{i}\right) \mu s^{2}\right)+\gamma r(s, p)+\alpha-p
$$

Consumer $i$ then decides to buy the good iff $\Delta u_{i} \geq 0$, that is

$$
\theta_{i} \geq \frac{p-\alpha-\left(\beta s-\mu s^{2} / 2\right)-\gamma r(s, p)}{\mu s^{2} / 2} \equiv \hat{\theta}(s, p)
$$

where $\hat{\theta}(s, p)$ is the threshold type above which consumers decide to purchase the good and below which they abstain; i.e. $u_{1 i}(s, p ; \hat{\theta})=u_{0 i}$. Assuming, for simplicity, a uniform distribution of types $\theta \sim U[0,1]$, the prestige utility reduces to ${ }^{8}$

$$
r(s, p)=E\left(\theta_{i} \mid \theta_{i} \geq \hat{\theta}\right)-E\left(\theta_{i}\right)=\frac{\hat{\theta}(s, p)}{2}
$$

The reputational gain from being a responsible consumer thus increases as the pool of these consumers narrows, i.e. the more it becomes a niche good that only the highest types purchase. Plugging this term into the consumer's incentive constraint, the threshold type $\hat{\theta}$ in the uniform case can be written as

$$
\hat{\theta}(s, p)=\frac{2(p-\alpha-\beta s)+s^{2}}{s^{2}+\gamma}
$$

and the aggregate demand becomes $D(s, p)=1-\hat{\theta}(s, p)$.

\footnotetext{
7 The authors give several examples on the importance of social prestige as a determinant for prosocial behavior such as purchasing hybrid cars, installing solar panels (versus indoor energy-efficient investments).

8 In general, $r(s, p)=\frac{\int_{\hat{\theta}(s, p)}^{1} \theta f(\theta) d \theta}{1-F(\hat{\theta})}$, i.e. the prestige utility is the conditional mean in the upper tail of the distribution of $\theta$. This reputational gain takes into account both the value of $\hat{\theta}$ and the weight attributed to $\theta_{i} \geq \hat{\theta}$, i.e. to which degree the product in question is a niche product.
} 


\subsection{Choice of the CSR-Price Bundle}

Assuming a constant marginal cost of production of the private good $c \in[0, \alpha)$ and given the total CSR investment $R(s, p)=s D$, (since $s$ represents the per unit monetary investment), the monopolist's profits are given by

$$
\pi(s, p)=(p-s-c) D(s, p)
$$

The timing of the game goes as follows. First, the monopolist maximizes his profits by deciding simultaneously on the CSR content of the product, $s^{u}$, and the price to be charged, $p^{u}$ (where the superscript $u$ denotes the unregulated scenario). Then, each consumers chooses whether or not to purchase one unit at most of the product. The following result obtains.

Proposition 1 The monopolist choice of the CSR-price bundle is given by

$$
\left(s^{u}, p^{u}\right)=\left(\frac{\gamma}{\mu} \times \frac{\beta-1}{(\alpha-c)+\frac{\gamma}{2}}, \frac{\mu\left(\left(\alpha+\frac{\gamma}{2}\right)^{2}-c^{2}\right)+\gamma\left(\beta^{2}-1\right)}{2 \mu\left((\alpha-c)+\frac{\gamma}{2}\right)}\right)
$$

if $\beta>1$ and $\gamma \neq 0$, and $\left(s_{0}^{u}, p_{0}^{u}\right)=\left(0, \frac{\alpha+c}{2}\right)$ otherwise (proof in the "Appendix")

By engaging in corporate social responsibility, the monopolist makes his product more valuable to consumers. However, he also incurs a cost by doing CSR. A necessary condition for the producer to engage in CSR is that consumers' interest in CSR, as measured by their social consciousness $\beta$, must be larger than the marginal cost of increasing CSR to the firm, which is 1 dollar. Thus, only when consumers place a sufficiently high value on CSR $(\beta>1)$ will the firm practice it.

Furthermore, under the assumption of heterogeneity in morally ideal levels of CSR, the firm has no incentives to invest in CSR when consumers do not account for the social prestige ( if $\gamma=0$ ). To see this, consider the firm's strategy absent reputational concerns. Given the varying ideal points of the different consumers, a firm may choose to target consumers either at the low or high end of the distribution of $\theta$. To target the lows, the firm would provide a relatively low level of CSR content per unit so as to be on the increasing part of as many warm glow curves as possible and expand its market coverage, at the cost of a reduced price so as to make its product appealing to those consumers with a low willingness to pay. Should the firm choose to target the highs, the CSR content as well as the price would have to be set at a relatively high level, this causes the firm to lose sales to consumers with relatively low $\theta$. Due to the assumption of unit demand together with the uniform distribution of types, under both strategies, the marginal cost of CSR (either in terms of a reduced market price or loss of sales to the lows) exceeds its marginal revenue (in the form of market expansion or higher price premium). ${ }^{9}$ When both conditions $\beta>1$ and $\gamma \neq 0$

\footnotetext{
${ }^{9}$ For instance, if the distribution of $\theta$ is sufficiently skewed to the right or if we allow for $q \in[0, \infty)$, the marginal revenue from targeting the highs with a larger CSR investment would exceed its costs and a positive CSR content is offered even in the absence of reputation concerns.
} 
are met, the monopolist commits to a positive level of CSR which allows him to charge a higher price and increase his margin which make the CSR investment worthwhile.

Proposition 1 shows the optimal per unit CSR effort to be equal to the weighted profitability of CSR relative to that of selling the private good, ${ }^{10}$ the weight being the reputation to ideal point concerns $\frac{\gamma}{\mu}$. A squeeze on the margin from sales of the private good induces the monopolist to seek a higher margin by investing more in CSR through a make-up effect; as if the producer had two businesses: selling the private good and investing in the public good, so that he could make up for the lower profitability of the former by a higher investment in the latter. The firm commits to a higher CSR content the lower the willingness to pay for its private product and the larger the marginal cost of its production. That is, a producer may choose a high CSR content of the good just because he is inefficient in the production (as captured by a high $c$ ) or the private good he sells is not strongly demanded on the market. The intuition behind this result is that the higher the cost of production, the more it pays for the firm to use CSR to expand the demand of its product or be able to charge a higher price for the CSR-private good bundle. ${ }^{11}$

The CSR content also increases in the reputation to ideal point concerns $\frac{\gamma}{\mu}$. With higher reputational concerns, the monopolist is able to charge a sufficiently high price for its CSR content due to the prestige utility it induces such that his profits increase despite the exclusion of consumers with lower levels of $\theta$. In contrast, an increase in $\mu$ limits the firm's ability to increase its CSR content since consumers then put a large weight on being close to their morally ideal contributions (which also decrease in $\mu$ ) and would not be willing to pay a large prime on the CSR effort that they deem unnecessary or exaggerated. The firm's pricing rule is obtained by setting $\frac{\partial \pi}{\partial p}=0$, which yields:

$$
p^{u}(s)=\frac{\alpha+c}{2}+\mathbb{I} s \frac{\gamma}{4}+\frac{\beta+1}{2} s
$$

The product price thus consists of the monopoly price absent any CSR efforts, a reputation prime, conditional on the product being linked to a CSR investment, and the price for CSR. The part of the price that is imputed to CSR consists of the per unit investment in the public good weighted by the premium the monopolist is able to charge for his CSR activities. Given the that $\beta$ has to exceed unity for the firm to engage in CSR, the price of per unit contribution exceeds one. That is, In a monopoly setup, each dollar contributed to social causes via the purchase of the impure public good costs the consumer more than one dollar. This result will be of interest for the welfare analysis, particularly, for the discussion of the surplus distribution between the consumers and the firm.

The following equations then characterize the equilibrium in the unregulated monopoly:

\footnotetext{
${ }^{10}$ Note that the term $\frac{\gamma}{2}$ appears throughout the paper as a markup independent of the level of CSR. This is because we assume that consumers derive the reputational gain from the act of purchasing the green product per se, which is not directly dependent on its CSR content. It is then perceived by the producer as a positive willingness to pay for his product. This term however disappears whenever $s=0$ due to the indicator function in (1).

11 This result relies on the assumption that both the public and private components of the good are substitutes in consumption.
} 


$$
\begin{aligned}
D^{u} & =\frac{\alpha+\frac{\gamma}{2}-c}{\gamma} \\
R^{u} & =\frac{\beta-1}{\mu} \\
\pi^{u} & =\frac{\left(\alpha+\frac{\gamma}{2}-c\right)^{2}}{2 \gamma}+\frac{(\beta-1)^{2}}{2 \mu} \\
C S^{u} & =\frac{(\beta-1)^{2}}{4 \mu}
\end{aligned}
$$

The parameters $\gamma, \beta$ and $\mu$ play an important role in determining the equilibrium on a market with CSR. A larger willigness to pay for CSR stemming from pure altruism (an increase in $\beta$ ) induces the firm to increase both the CSR content and the unit price for CSR. The group of consumers financing the firm's CSR investment remains unchanged, however aggregate investment increases in $\beta$ since the contribution per consumer increases and firms earn higher profits on their CSR efforts. A higher commitment to ideal points (larger $\mu$ ) however has the opposite effect on the CSR market. It results in a lower CSR content and market price. The pool of consumers purchasing the good remaining unchanged, the firm's CSR investment falls. Higher eputational concerns, $\gamma$ induce both a higher equilibrium price, but narrows the pool of buyers at equilibrium. Despite the decrease in the demand, the firm's total CSR investment at equilibrium remains unaffected by the prestige effect. In sum, higher social image concerns do not alter the firm's total CSR investment but rather restrict the financing of this investment to consumers with larger morally ideal contributions, and higher altruism increases the CSR investment without affecting the demand.

It should be noted that, at equilibrium, all consumer sruplus from both the social image and the private good consumption is extracted by the producer and consumers obtain a positive surplus from warm glow. To assess the welfare gains from CSR, let $W(s, p)$ denote the social welfare that consists of consumer surplus and the firm profits, i.e.

$$
W(s, p)=C S(s, p)+\pi(s, p)
$$

Plugging the equilibrium values into the welfare function, CSR is found to be welfareimproving, and hence desirable, if consumer's sensitivity to such activities, as captured by $\beta$, is sufficiently large and their commitment to their ideal points, $\mu$ sufficiently small. The following lemma formalizes this statement.

Lemma 2 CSR is welfare improving iff $\beta>1+\sqrt{\mu(\alpha-c)(2+\alpha-c)}$ (proof in the "Appendix").

This lemma states that, introducing CSR on the market is desirable only if consumers' interest in CSR is sufficiently large relative to their commitment to their ideal points and to the margin on the private good market. Recall that, as $\beta$ increases, the monopolist increases, not only the per unit CSR efforts, but also the prime on CSR. The price then increases, and this has two sets of effects on consumers' surplus. On the one hand, a group of consumers is excluded from the market and experiences a loss in utility from the consumption of the private good that we assume to be unavailable otherwise. On the other hand, the remaining buyers benefit from a warm glow surplus and all consumers derive 
a positive utility from the increased level of public good available. Thus the overall gain exceeds the loss of the excluded group only if consumers put a sufficiently large value on CSR relative to the private good itself. Otherwise, consumers are better off consuming the private good with no CSR content. Furthermore, the more committed consumers are to their ideal points, the less desirable is CSR.

It should be noted here that CSR being welfare improving does not prevent the possibility of it being a means of redistribution of surplus from the consumers to the producer due to the prime the monopolist charges on consumers' contributions to the public good through CSR and the reputation prime. Hence, unless the monopolist has a comparative advantage in providing this particular public good, this is perhaps not the most efficient means for the private provision of public goods.

Next, we consider a three-stage game where a regulator first sets a tax ( setting $\mu=1$ for the rest of the analysis). The firm then decides whether or not he will engage in CSR activities and chooses the CSR-price bundle as to maximize its profits. Each consumer, given his $\theta_{i}$, forms his demand taking into account the tax rate set by the government and the price and per unit contributions set by the producer. Finally, the regulator uses the collected taxes to provide a certain amount of the public good, which can complement or substitute for the firm's CSR investment.

\section{Regulated Scenario}

The analysis here focuses on characterizing the firm's response to the regulator's tax policy, which can be either a specific or an ad valorem tax, and establishing comparative statics of each considered in isolation. The possibility of the regulator mixing between the two instruments will only be considered in Sect. (3.2) for comparison purposes.

\subsection{Second-Stage Outcome}

The game will be solved backwards. The point of departure is thus the subgame played by the firm and consumers in the final stage after the government has decided on the tax rate to be imposed. Introducing ad valorem taxation at the rate $t \in[0,1)$ the monopolist's aftertax profits become ${ }^{12}$

$$
\pi(s, p, t)=((1-t) p-s-c) D(s, p)
$$

and, given a specific tax, $\tau$, profits are given by

$$
\pi(s, p, \tau)=(p-\tau-s-c) D(s, p)
$$

Again, the pricing rules under ad valorem taxation and a specific tax are derived from the respective first order condition as

\footnotetext{
12 Note that in the welfare analysis, we relax the assumption that $t \in[0,1)$ and allow for negative values of $t$
} 


$$
\begin{aligned}
& p(s, t)=\frac{\alpha+c \lambda}{2}+\frac{\gamma}{4}+\frac{\beta+\lambda}{2} s(t) \\
& p(s, \tau)=\frac{\alpha+(c+\tau)}{2}+\frac{\gamma}{4}+\frac{\beta+1}{2} s(\tau)
\end{aligned}
$$

where

$$
\lambda=\frac{1}{1-t}
$$

is the perceived increase in marginal costs from ad valorem taxation (note that $\lambda \geq 1$ ). Unlike the ad valorem tax that is perceived as a proportional increase in the marginal costs of both the firm's activities, namley CSR and the private good production, the specific tax is seen as an increase in the marginal cost of the private good production. In our model, CSR content is seen as a product characteristic or attribute (such as quality). Since all characteristics of the product are reflected in consumer price, an ad valorem tax bears on CSR as well. Given a specific tax however, CSR remains an untaxed attribute since it is not related - at least not directly - to the quantity produced of the product that is being taxed. The following proposition then shows the optimal price-CSR bundle under each tax instrument.

Proposition 3 To maximize his after-tax profits, the monopolist chooses the bundle

(i) Given an ad valorem tax, $t$,

$$
\left(s^{t}, p^{t}\right)=\left(\frac{\gamma(\beta-\lambda)}{\alpha+\frac{\gamma}{2}-c \lambda}, \frac{\left(\alpha+\frac{\gamma}{2}\right)^{2}-c^{2} \lambda^{2}+\gamma\left(\beta^{2}-\lambda^{2}\right)}{2\left(\alpha+\frac{\gamma}{2}-c \lambda\right)}\right)
$$

if $\beta>\lambda$ and $\alpha+\frac{\gamma}{2}>c \lambda$, and $\left(s_{0}^{t}, p_{0}^{t}\right)=\left(0, \frac{\alpha+c \lambda}{2}\right)$ otherwise, and

(ii) Under a specific tax, $\tau$,

$$
\begin{aligned}
& \left(s^{\tau}, p^{\tau}\right)=\left(\frac{\gamma(\beta-1)}{\left(\alpha+\frac{\gamma}{2}\right)-(c+\tau)}, \frac{\left(\alpha+\frac{\gamma}{2}\right)^{2}-(c+\tau)^{2}+\gamma\left(\beta^{2}-1\right)}{2\left[\left(\alpha+\frac{\gamma}{2}\right)-(c+\tau)\right]}\right) \\
& \text { if } \alpha+\frac{\gamma}{2}>c+\tau, \text { and }\left(s_{0}^{t}, p_{0}^{t}\right)=\left(0, \frac{\alpha+c+\tau}{2}\right) \text { otherwise }
\end{aligned}
$$

This proposition states that CSR is feasible only if the marginal willingness to pay for CSR activities covers the augmented marginal cost of CSR and the marginal willingness to pay for the private good exceeds the taxed marginal cost of production. If the above conditions hold, the firm has an incentive to provide a positive level of CSR when complying to the tax rate set by the regulator. Otherwise, the firm will have no incentive to engage in CSR, it will pay the taxes imposed and produce only the private good, provided $\alpha>c \lambda$ under ad valorem taxation or $\alpha>c+\tau$ given a specific tax.

Two aspects of the tax incidence are of particular interest here, namely, the effects of an ad valorem versus a specific tax on the CSR content of the product and the price. A priori, one would expect the increase in the tax rate to decrease the CSR effort of the producer 
who now incurs higher costs. We find however that imposing a tax does not necessarily have a repressive effect on the CSR attribute.

Lemma 4 While a specific tax always results in increased per unit CSR contributions, an ad valorem tax increases the CSR content of the product iff $\frac{\beta}{1}>\frac{\alpha+\frac{\gamma}{2}}{c}$, and decreases it otherwise.

It can be seen from Proposition (3) that the optimal choice of per unit CSR is equal to the margin on CSR relative to the non-CSR margin. The latter include the margin from the private product sales and the prime on reputation (since this particular margin is related to the act of purchasing per se and not directly related to the level of CSR). Since a specific tax bears only on the private consumption attribute of the product while CSR remains untaxed, the relative profitability of the latter increases. The firm has incentives to enhance the CSR attribute to compensate for the now lower margin on the private component through the make up effect previously discussed. The monopolist thus always increases per unit CSR as a response to the specific $\operatorname{tax}^{13}$ since the relative profitability of this activity always increases.

Unlike the unit tax, ad valorem taxation reduces absolute profitabilities from both activities by inflating their marginal costs, though not necessarily proportionally. The firm increases its per unit CSR investment if its profitability, in relative terms, increases, which occurs if the marginal revenue to marginal cost is higher for CSR (i.e. $\frac{\beta}{1}>\frac{\alpha+\frac{1}{2}}{c}$ ), and reduces it otherwise. These results on the tax incidence on the CSR content (except for the case where per unit CSR increases with an ad valorem tax) are consistent with the findings of the literature on vertical product differentiation (Kay and Keen 1983; Cremer and Thisse 1994) which found ad valorem taxation to reduce product quality and specific taxes to enhance it.

It is now possible to examine the tax incidence on the price. Recall that the monopolist sets his price as a markup on both the marginal cost of producing the private good and the CSR content of the product (in addition to the reputation prime which is unaffected by the tax). It can be easily seen from (6) that, when a unit tax is imposed, both the mark-up on the private commodity and the CSR content increase. Since the tax is perceived as a marginal cost increase, the monopolist is likely to overshift the specific tax. Overshifting is said to occur when the rise in price exceeds the amount of the tax (i.e. $d p / d t>1$ ). We find that the specific tax is overshifted whenever

$$
\gamma\left(\beta^{2}-1\right)>\left[\left(\alpha+\frac{\gamma}{2}\right)-(c+\tau)\right]^{2}
$$

Thus, when the willingness to pay for CSR, either stemming from pure altruism, $\beta$, or pursuit of social prestige, $\gamma$, is sufficiently large, the monopolist considerably increases the (untaxed) CSR content of his product and succeeds in passing the entire tax over to consumers along with a price increase. An ad valorem tax, on the other hand, is less likely to be overshifted. In particular, overshifting of the specific tax is a necessary but not sufficient condition for overshifting of the ad valorem tax (see "Proof of Proposition 5" section in "Appendix"). This finding extends the overshifting results in Delipalla and O'Donnell (2007) and Delipalla and Keen (1992) to a market with CSR.

13 Note that $\frac{d s}{d \tau}=\frac{\gamma(\beta-1)}{\left[\left(\alpha+\frac{\gamma}{2}\right)-(c+\tau)\right]^{2}}$ which is always positive. 
Let $G$ denote the tax revenues collected by the regulator. The equilibrium under an ad valorem tax is then characterized by:

$$
\begin{aligned}
G^{t} & =t p^{t} D^{t} \\
D^{t} & =\frac{\alpha+\frac{\gamma}{2}-c \lambda}{\gamma} \\
R^{t} & =\beta-\lambda \\
\pi^{t} & =\frac{\left(\alpha+\frac{\gamma}{2}-c \lambda\right)^{2}+\gamma(\beta-\lambda)^{2}}{2 \gamma \lambda}
\end{aligned}
$$

Whereas given a specific tax, the market equilibrium turns out to be

$$
\begin{aligned}
G^{\tau} & =\tau D^{\tau} \\
D^{\tau} & =\frac{\left(\alpha+\frac{\gamma}{2}\right)-(c+\tau)}{\gamma} \\
R^{\tau} & =\beta-1 \\
\pi^{\tau} & =\frac{\left[\left(\alpha+\frac{\gamma}{2}\right)-(c+\tau)\right]^{2}+\gamma(\beta-1)^{2}}{2 \gamma}
\end{aligned}
$$

Thus, compared to the unregulated scenario, both forms of taxation result in a narrower group of consumers purchasing the good at equilibrium. This effect is somewhat offset the larger the reputation concerns (i.e. $\frac{\partial D}{\partial t}<0$ and $\frac{\partial^{2} D}{\partial t \partial \gamma}>0$ ). That is, the more social image is valued among consumers, the fewer the consumers that will be excluded out of the market due to the tax. It is interesting to note that, whether per unit CSR increases or decreases, the firm's total CSR investment always decrease in the ad valorem tax and remain unchanged under specific taxation. Furthermore, while an ad valorem tax reduces the firm's profits from both activities, a specific tax reduces only the profits on the private component of the good.

\subsection{Ad Valorem Versus Specific Tax}

To provide a basis for the welfare comparison of the ad valorem and unit tax, we assume the regulator is able to mix between the two instruments, the tax yield is then given by

$$
G(t, \tau)=(t p+\tau) D
$$

Consider a shift in the policy mix in favor of a larger ad valorem tax, while maintaining the tax revenues level at the initial equilibrium price; i.e.

$$
p d t=-d \tau>0
$$

This is essentially the P-shift analysis in Delipalla and Keen (1992) amended for our setup. The description here will be brief (we refer the reader to "Proof of Proposition 5" section in "Appendix" for a more comprehensive analysis). The following proposition then summarizes the effects of tilting the balance of the policy mix towards more reliance on ad valorem taxes on the different endogeneous variables of the model. 
Proposition 5 Under the equal-tax revenues criterion, compared to unit taxes, ad valorem taxes induce (proof in the "Appendix")

(i) less CSR content and a lower price,

(ii) an unambiguously higher demand,

(iii) the same aggregate profits (but less profits from CSR and more profits from the private good), and

(iv) less total CSR investment.

Proposition 5 states that a shift towards higher ad valorem taxation reduces the CSR content of the product. This result is straightforward in the case where an ad valorem tax induces a lower per unit CSR. However, even over the range of parameters where both instruments result in a higher CSR content, this effect will be larger under the unit tax. Intuitively, with a specific tax, the absolute profitability of CSR remains unchanged and its relative profitability always increases since the tax only reduces the margin on the private good (see Proposition 3). Whereas, given an ad valorem tax, the absolute profitability of CSR always falls and any increase in its relative profitability results from an even larger decline in the margin on the private good.

Consequently, the price increase imputed to the CSR content adjustment is always larger under a specific tax. Furthermore, the rise in the mark up on the private good is also likely to be larger in the case of a specific tax which is perceived as an increased marginal cost (see the pricing rule in (6)). These two observations combined explain the larger price increase as well as the higher likelihood of overshifting under a unit tax. This also causes the decline in demand to be considerably larger with specific taxes. Ad valorem taxes are then said to perform better in terms of revenue extraction (Suits and Musgrave 1953; Dröge and Schröder 2009) as the same tax yield can be obtained at a lower price and a higher quantity.

The unit tax appears to be superior however in terms of maintaining the firm's total CSR investment, the latter being only affected by ad valorem taxation. A P-shift from specific to ad valorem taxation is found to have a neutral effect on aggregate profits. This result is consistent with the literature on taxation in monopoly settings (Delipalla and Keen 1992). The novel finding here however is that the P-shift changes the monopolist's profits structure. Precisely, it increases profits from sales of the private good at the cost of reduced profits on the CSR market.

To summarize, for a given level of tax revenues, an ad valorem tax outperforms the unit tax on the private good market: it results in a lower price, a higher demand and increased profits for the firm. This occurs at the cost of a reduced margin on CSR resulting in less incentives to engage in these activities. The firm's total CSR contributions thus fall. The specific tax, on the other hand, ensures larger profitability of CSR activities and hence is superior in terms of enhancing the firm's investment in the public good, with the cost here being the exclusion of more consumers from consumption of the private good and reduced profits from its sales.

These results suggests that if the regulator thinks the level of private investment is about right in the no-tax equilibrium but wishes to raise some revenue then it would be reasonable to impose a specific tax. Conversely, if the CSR investment is unnecessarily high, he can reduce it by setting an ad valorem tax. In that sense, the ad valorem tax has a corrective function whereas the specific tax has a redistributive one. 
With these insights on the comparative statics of the two instruments, we now turn to stage one of the taxation game where the regulator decides on the tax to be imposed.

\section{Optimal Tax Structure}

There is a single welfare-maximizing regulator, raising revenue only through taxes, either ad valorem or specific, on products. Tax revenues are meant for public good provision in order to benefit consumers. Unlike the unregulated scenario where the overall level of public good in the economy, $Y$, coincides with the total monopolist CSR investment, $R$, after the government intervention it becomes

$$
Y_{k}^{j}=Y_{k}\left(G^{j}, R^{j}\right)
$$

The aggregate level of public good thus depends on both the tax instrument $j \in\{t, \tau\}$ and the production technology, $k \in\{s u b$, comp $\}$ which determines the functional form of $Y$ under the substitution and the complementarity scenarios respectively. Given the tax instrument $j$ and the production technology of the public good $k$, the social welfare is given by

$$
W_{k}^{j}=C S_{k}^{j}+\pi^{j}
$$

The regulator then chooses the tax that yields the largest welfare $W_{k}^{*}=\max \left\{W_{k}^{t}, W_{k}^{\tau}\right\}$.

\subsection{Substitutable Private and Public Investments}

Assuming the firm's CSR investment and the government's provision are perfectly substitutable, the aggregate level of public good when the tax instrument $j$ is applied, is ${ }^{14}$

$$
Y_{\text {sub }}^{j}\left(G^{j}, R^{j}\right)=G^{j}+S^{j}
$$

This simple additive function allows us to compute closed-form expressions of the optimal tax and total surplus for both the ad valorem and the unit tax, which are then compared to provide further intuition about how the regulator's choice among the two tax instruments depends on the parameters of the model. This optimal tax choice appears to depend crucially on the interplay between consumers' pure altruism, $\beta$, and their social image concerns, $\gamma$, as indicated in the following proposition.

Proposition 6 When the monopolist's CSR and the public investments are substitutes, there exists a threshold value $\beta_{1}^{\text {crit }}=\frac{2 c^{2}}{\gamma}$ such that

- When $\beta>\beta_{1}^{\text {crit }}$, a positive ad valorem tax always dominates a specific tax, and is given by

\footnotetext{
${ }^{14}$ The additive production function assumed here means that a dollar that comes from firm's contributions to the public good through CSR will help finance the project the same way that a dollar that comes from the government would.
} 


$$
t_{s u b}^{*}=\frac{\gamma(\beta+1)}{\gamma \beta-2 c^{2}}
$$

- When $\beta=\beta_{1}^{\text {crit }}, t_{\text {sub }}^{*}=\tau_{\text {sub }}^{*}=0$.

- When $\beta<\beta_{1}^{\text {crit }}$, an ad valorem subsidy given by (10) is optimal. (proof in the "Appendix")

Proposition 6 states that ad valorem taxation always dominates specific taxes when the public and private investments are substitutable. A specific tax reduces both the firm's profits on the private commodity market considerably. A positive tax can then be justified in the case where the welfare gain from the tax revenues - that we assume here to be recycled in the (additive) form of a public good-compensates for its negative effect. However, since a unit tax induces a relatively large increase in the price, the demand decreases considerably, which translates into a reduced tax base. That is, the amount of purchases that are being taxed decreases which weighs negatively on the tax revenues and hence on the government provision of the public good.

An ad valorem tax, on the other hand, is a more efficient revenue extractor and hence can be welfare-improving. There are two prerequisites, however, for the optimal ad valorem tax to be positive (i.e. for $\beta>\frac{2 c^{2}}{\gamma}$ ): a relatively high social consciousness of consumers and reputational concerns that are not too low. The idea here is that, when the CSR market is performing well (large $\beta$ ), the regulator ought to crowd-out part of the firm's investment in the public good by extracting revenues from both the consumers' surplus from altruism and the firm's profits to generate revenues for the public provision by the government. This strategy has to be supported by reputational concerns that are not too low (that is, a relatively inelastic demand), otherwise the pool of buyers narrows considerably and the ad valorem tax loses its function as a revenue extractor. Also note that an ad valorem tax is more likely to be positive when the monopolist is sufficiently efficient in the production of the private good (that is, $c$ is sufficiently low). Since ad valorem taxation extracts revenues from the firm's profits on both the CSR and the private commodity markets, it has to be the case that the producer can afford a squeeze on the margin for a positive tax to be imposed.

If altruism among consumers is high but reputational concerns are sufficiently low, a better strategy would be to capitalize on the firm's CSR investment by providing an ad valorem subsidy which would have a multiplier effect on the CSR activities profitability (since the margin on CSR is initially large in this case). Finally, note that a specific subsidy is never optimal in the subsitution scenario as it would simply boost the private good market at the expense of the public good provision.

\subsection{Complementary Investments in the Public Good}

Let us now consider the situation where the private and public investments are complements. The production technology of the public good is such that

$$
Y_{\text {comp }}^{j}\left(G^{j}, R^{j}\right)=G^{j} \times S^{j}
$$

Thus the private firm's investment in CSR is assumed to enhance the government's provision of the public good. This could be thought of as the firm drawing on its technical expertise to contribute to the public good so that the private investment enhances the public provision. Alternatively, this could be seen as the government's provision of the necessary 
infrastructure being indispensable for the firm's investment to be meaningful. The interplay between consumers' social consciousness, $\beta$, and their reputational concerns, $\gamma$, still determines the optimal tax policy, although quite differently.

Proposition 7 Define $\beta_{2}^{\text {crit }} \quad$ and $\quad \beta_{3}^{\text {crit }}$ as $\quad \beta_{3}^{\text {crit }}=\frac{c^{2}-\sqrt{\left(c^{2}+2 \gamma\right)^{2}-4 \gamma\left(\alpha+\frac{\gamma}{2}\right)^{2}}}{2 \gamma} \quad$ and $\beta_{3}^{\text {crit }}=\frac{c^{2}+\sqrt{\left(c^{2}+2 \gamma\right)^{2}-4 \gamma\left(\alpha+\frac{\gamma}{2}\right)^{2}}}{2 \gamma}$. In the complementarity case, a welfare-maximizing regulator optimally sets

- Under ad valorem taxation: a positive ad valorem tax $t_{\text {comp }}^{*}>0$ under the sufficientbut not necessary - condition that

$$
\beta_{2}^{\text {crit }} \leq \beta \leq \beta_{3}^{\text {crit }}
$$

- Under the unit tax scheme: a specific tax given by

$$
\tau_{\text {comp }}^{*}=\frac{\left(\alpha-c+\frac{\gamma}{2}\right)(\beta-2)}{2 \beta-3},
$$

which is positive whenever $\beta>2$, null if $\beta=2$ and negative if $\frac{3}{2}<\beta<2$. (proof in the "Appendix")

In the complementarity scenario, the firm's CSR investment is regarded as a catalyst for the government's provision of the public good. ${ }^{15}$ Thus, the crowding-out effect of the CSR investment is particularly important here since it reduces the value for the public investment multiplier. Fortunately, under a specific tax, the value of the multiplier is not affected. This explains the finding in Proposition 7 that the only requirement for a positive unit tax is a high level of altruism (i.e. $\beta>2$ ).

It should also be noted that the specific tax increases in the reputational concerns and decreases in consumers' altruism. Put differently, while higher reputational concerns call for larger specific taxes (smaller unit subsidies), higher altruism calls for smaller specific taxes (larger unit subsidies). Intuitively, since specific taxes will likely be overshifted onto consumers, the less elastic their demand is (higher $\gamma$ ), the larger the tax that can be imposed without compromising the tax base. Altruism however has an opposite effect since it reduces the need for taxation. The better the CSR market outcomes, the less the need for tax revenues for the public provision.

For a positive ad valorem tax however to be optimal, relatively low levels of consumers' altruism are needed (for $\beta \leq \beta_{3}^{\text {crit }}$ ). That is, contrary to the substitution case where high levels of altruism were required to enable extraction of revenues from the CSR market, altruism reduces the welfare gains from a positive ad valorem tax in the complementarity case. This finding is related to the fact that when both investments are rather complements and $\beta$ is large, a better strategy would be to extract the minimal amount of tax necessary to boost the firm's CSR investment and thus support the private provision of the public good.

\footnotetext{
15 That is, a unit increase in the public provision, $G$, adds to the welfare $\beta-1$ units under a specific tax and $\beta-\lambda$ units with an ad valorem tax (see equilibrium values in (7) and (8)).
} 
In a sense, these findings suggest that an ad valorem tax is a tax on altruism and is an efficient extractor of revenues to finance the public good provision when the firm's provision thereof is insufficient, whereas a specific tax is rather imposed on prestige to enhance the market provision of CSR when it is already at a decent level. The intuition behind this result has parallels in the public economics literature which finds ad valorem taxes to outperform the specific tax when the objective is the tax yield (Jørgensen and Schröder 2005; Delipalla and Keen 1992) but the specific tax to be more efficient when the aim is rather to correct some externality (Dröge and Schröder 2009).

\subsection{Discussion}

Consider the choice between an ad valorem and a specific tax. When the firm's CSR investment and the government's are regarded as substitutes, for instance when CSR consists in philanthropic activities of the firm where no comparative advantage or complementarities are expected, tax exemptions or subsidies may be justified when consumers' both social and reputational concerns are sufficiently low or when the private good market is not performing well. In this case, an ad valorem subsidy is welfare superior to a specific one. However, when the interest in CSR, either due to altruism or social prestige is high, exemptions appear to be suboptimal and an ad valorem tax can be welfare improving.

When the private and public investments are complements. Although no formal mathematical condition could be derived, the intuition behind this choice is presented. The desirability of a specific tax depends on three questions: is the level of private investment prior to the intervention about right? Are social image concerns sufficiently high? Will a squeeze on the producer's margin from the private good sales generate enough revenues? If the answer to all questions is positive, then it is likely that intervention through specific tax dominates ad valorem taxation.

Specifically, for relatively low values of $\beta$, i.e. $\beta<\beta_{2}^{\text {crit }}$, either an ad valorem subsidy or no intervention dominate a specific subsidy. Intuitively, when $\beta$ is small, the initial CSR investment is quite low. While a specific subsidy, at best, would increase welfare on the private good market, an ad valorem subsidy boosts the CSR investment by increasing the firms' profits on such activities at the expense of a reduced government's provision of the public good. This makes economic sense when the firm's CSR investment is valued more than the government's. For instance, if the public good in question consists of reducing industrial emissions, then it is a plausible assumption that the firm's investment is to be given a higher weight. Tax exemptions or ad valorem subsidies are, in this case, justified even at the cost of reduced public spending on such activities.

For higher levels of consumers' altruism, the optimal tax instrument depends on the prevailing level of reputation concerns. With an ad valorem tax, there is a trade-off: on the one hand, a larger tax allows for a larger extraction of revenues from the market surplus, but on the other, it reduces the multiplier effect of the firm's CSR investment on the government's provision. Under a specific tax, only the revenue extraction effect is relevant since the value of the multiplier is not affected. This suggests that a specific tax would be welfare superior. However, the regulator's ability to extract revenues with a unit tax is limited by the image concerns parameter. Only when $\gamma$ is sufficiently large (low price elasticity of demand) will the gain from the tax yield generated by the specific tax offset its costs.

Hence, a specific tax outperforms ad valorem taxation for relatively larger values of $\beta$ when consumers sufficiently value social image. This implies that, on markets where altruism is high but not excessively so, the relative appeal of a unit tax versus ad valorem 
taxation increases as reputational concerns increase. In other words, when altruism is relevant but, most importantly, where the visibility of responsible consumption is sufficiently high (the markets for hybrid cars or solar panels for instance), welfare gains are to be expected from introducing a specific tax. In general, while an increase in consumers' reputational concerns always increases the relative attraction of specific taxes, an increase in their social consciousness renders ad valorem taxation more appealing.

\section{Conclusion}

This paper shows how the regulator's decision to exempt CSR firms from taxes should depend on the nature of the CSR investment when consumers experience both a warm glow and prestige benefit from buying ethical products. While CSR investments are typically considered and analyzed as a welfare-improving variable that needs to be promoted, our results indicate the need for CSR efforts to be integrated within the broader framework of public good provision in the economy. Incentives offered to CSR firms need to be adjusted to market characteristics, the prevailing level of altruism and reputational concerns in particular, and the nature of interdependence with the public provision of public goods (namely whether both forms of investment are substitutes or complements) to maximize returns.

Our analysis revealed several interesting results. It is found that, in terms of welfare, the effects of ad valorem taxes versus specific taxes are quite different. An ad valorem tax is an efficient revenue extractor, it results in a lower price, higher output, higher profits on the private good market but lower CSR investment by the firm. On the other hand, a revenueequivalent specific tax results in overshifting of the tax and higher prices, lower profits on the private good market, but better performance on the CSR market in terms of profits and CSR investment than an ad valorem tax.

In terms of welfare ranking, two scenarios are considered. In the case where the tax revenues finance a public good that could substitute for the firm's CSR investment, tax exemptions may only be justified when the prevailing levels of altruism and reputational concerns among consumers are sufficiently low, otherwise an ad valorem tax is optimal. When the public good in question requires both the government and the firm's investment, then ad valorem taxes are welfare superior if the firm's initial investment in the public good is sufficiently low, otherwise, a specific tax outperforms ad valorem taxation, particularly when social image concerns are relatively high.

In terms of policy, our results have clear implications regarding the regulation of markets with CSR. Instead of advocating tax exemptions for CSR, we find that the tax policy should be chosen more carefully, taking into account both the characteristics of consumers on the relevant market as well as the nature of the CSR being provided on the market. ${ }^{16}$ On markets where the green consumption is visibly prestigious, an undue reliance on exemptions might have an opportunity cost in terms of forgone tax revenues that could have financed the public good provision. A market where consumers have, on average, a high demand for firms to engage in CSR and value the private good to which CSR investments are linked, would benefit from government intervention through ad valorem taxation.

\footnotetext{
16 A case in point is the example presented in the introduction of the decision of the Ministry of Corporate Affairs in India to exempt from taxes only particular CSR activities.
} 
In that particular case, taxing CSR products is welfare improving and can serve as a means of progressive taxation, whereby more taxes are levied on wealthier consumers-if one admits the degree of altruism to be positively related to income-to make the public good available to everyone. Provided that the proceeds from taxation are used to enhance the productivity of such investments, taxing CSR in this case is said to yield a double dividend, namely the higher level of public good and the additional redistributional benefit that the tax enables.

Our research also has several limitations. We have considered a constant cost for CSR activities that is separable from the standard production cost. It is likely that the supply curve is upward sloping, for example, when the public good in question is the reduction of environmental impact from a natural resource in finite supply. Further, relaxing the assumption about additive separability of private good and the public add-on in consumers' utility function may also offer some new insights. Moreover, one of the limitations of the model is that a monopoly market is considered without examining the strategic effect of consumers' image concerns on firms' choices in more competitive setups, or even further, if repuatational concerns would have an effect on determining the market structure. Finally, since CSR are typically communicated by firms engaging in CSR, it remains questionable whether these activities meet the high levels as claimed. Modelling how reputation will be defined given this moral hazard problem between the firm and consumers about CSR is both a challenging and interesting area of research.

Acknowledgements The author would like to thank the anonymous referee from the French Association of Environmental and Resource Economists (FAERE) for the comments and suggestions on an earlier draft of the paper.

\section{Appendix}

\section{Proof of Proposition 1}

Optimal values are obtained by solving simultaneously the first order conditions $\frac{\partial \pi(s, p)}{\partial p}=\frac{\partial \pi(s, p)}{\partial s}=0$. Two critical points obtain $\left(s_{1}=\frac{\gamma(\beta-1)}{\mu(\alpha+\gamma-c)}, p_{1}=\frac{\mu\left[(\alpha+\gamma)^{2}-c^{2}\right]+\gamma\left(\beta^{2}-1\right)}{2 \mu(\alpha+\gamma-c)}\right)$ and $\left(s_{2}=-\frac{\alpha+\gamma-c}{\beta-1}, \quad p_{2}=\frac{\beta c-\gamma-\alpha}{\beta-1}\right)$. Checking the second-order conditions, we find that $H_{1}=\pi_{p p}=-\frac{4}{\mu s^{2}+\gamma}$ which is always negative. The determinants of the corresponding Hessian matrices however are $\left.H_{2}\right|_{s_{1}, p_{1}}=-\frac{4(\alpha+\gamma-c)^{6} \mu^{3}}{\gamma^{3} X^{2}}>0$ and $\left.H_{2}\right|_{s_{2}, p_{2}}=\frac{4(\beta-1)^{6}}{X^{2}}<0$, where $X=\gamma \mu(\gamma+2(\alpha-c))+\mu(\alpha-c)^{2}+\gamma \beta(\beta-1)^{2}$. Hence $\left(s_{1}, p_{1}\right)$ is clearly a maximum whereas $\left(s_{2}, p_{2}\right)$ is a saddle point.

\section{Proof of Lemma 2}

In the absence of CSR activities, the market outcomes coincide to the standard monopoly, where the producer maximizes profits given by $\pi(p)=(p-c) D(p)$ where $D(p)=\alpha-p$. The equilibrium output, price and profits are, respectively, $Q^{0}=\frac{\alpha-c}{2}, p^{0}=\frac{\alpha+c}{\alpha^{2} c}$ and $\pi^{0}=\frac{(\alpha-c)^{2}}{4}$. Consumers' surplus is simply given by $C S^{0}=\int_{0}^{1}(\alpha-p) f(\theta) \stackrel{2}{d} \theta+Y=\frac{\alpha^{2} c}{2}+0$, assuming in this scenario that the overall level of public good is null since there is no government intervention.

In the CSR case, total consumer surplus is 


$$
\begin{aligned}
C S\left(s^{*}, p^{*}\right) & =\int_{\theta=0}^{1}\left[\beta s-(1-\theta) \mu \frac{s^{2}}{2}+\gamma \frac{\hat{\theta}}{2}+\alpha-p+Y\right] f(\theta) d \theta \\
& =\left(\beta s-\mu \frac{s^{2}}{2}+\gamma \frac{\hat{\theta}}{2}+\alpha-p\right) D(s, p)+\mu \frac{s^{2}}{2}\left(\frac{1-\hat{\theta}^{2}}{2}\right)+s D(s, p)
\end{aligned}
$$

Finally plugging in the equilibrium value, this expression reduces to $C S^{u}$ given in (5). Total welfare in the benchmark model with CSR activities is thus greater than in the absence of CSR iff $C S^{u}+\pi^{u}>C S^{0}+\pi^{0}$, that we rearrange to obtain the condition in the lemma.

\section{Proof of Proposition 5}

The monopolist's perceived after-tax profits are $\pi=((1-t) p-\tau-s-c) D(s, p)$, and the pricing rule obtains as

$$
p^{*}(s)=\frac{\alpha+(c+\tau) \lambda}{2}+\frac{\gamma}{4}+\frac{\beta+\lambda}{2} s
$$

The optimal CSR-price bundle is then (where the superscript $m$ denotes the equilibrium under policy mix):

$$
\begin{aligned}
s^{m} & =\frac{\gamma(\beta-\lambda)}{\alpha+\frac{\gamma}{2}-(c+\tau) \lambda} \\
p^{m} & =\frac{\left(\alpha+\frac{\gamma}{2}\right)^{2}-(c+\tau)^{2} \lambda^{2}+\gamma\left(\beta^{2}-\lambda^{2}\right)}{2\left(\alpha+\frac{\gamma}{2}-(c+\tau) \lambda\right)}
\end{aligned}
$$

And the equilibrium is characterized by

$$
\begin{aligned}
D^{m} & =\frac{\left(\alpha+\frac{\gamma}{2}\right)-(c+\tau) \lambda}{\gamma} \\
R^{m} & =\beta-\lambda \\
\pi^{m} & =\frac{\left[\left(\alpha+\frac{\gamma}{2}\right)-(c+\tau) \lambda\right]^{2}+\gamma(\beta-\lambda)^{2}}{2 \gamma \lambda}
\end{aligned}
$$

- A simple comparative statics exercise shows that

$$
\frac{\partial s^{m}}{\partial t}=\phi_{s} \frac{\partial s^{m}}{\partial \tau}, \text { with } \phi_{s}=\frac{-\left[\left(\alpha+\frac{\gamma}{2}\right)-\beta(c+\tau)\right]}{\beta(1-t)-1}
$$

The total effect of the reform on the CSR content, plugging in the reform definition in (9), is then given by 


$$
\begin{aligned}
d s & =\frac{\partial s^{m}}{\partial t} d t+\frac{\partial s^{m}}{\partial \tau} d \tau \\
& =-\left(p^{m}-\phi_{s}\right) \frac{\partial s^{m}}{\partial \tau} d t
\end{aligned}
$$

We find that $d s<0$ since $\left(p-\phi_{s}\right)>0, \frac{\partial s^{m}}{\partial \tau}>0$ and $d t>0$.

- By the same token, we find the results for the effect on $d P$. Defining the coefficient for the relative effects on the price as $\phi_{p}=\frac{(\partial p / \partial d t)}{(\partial p / \partial d \tau)}$, we then have

$$
p^{m}-\phi_{p}=G(t, \tau)[G(t, \tau)+4 \gamma \beta(1-t)]>0
$$

where $G(t, \tau)=[(\alpha+\gamma)(1-t)-(c+\tau)]^{2}+\gamma[\beta(1-t)-1]^{2}$ and $\frac{\partial p^{m}}{\partial \tau}>0$. Then, using the analog of (14) for the effect on the price, we fnd that $d p>0$.

To see that overshifting is less likely under ad valorem taxation, observe that $p>\frac{\partial P}{\partial t} / \frac{\partial P}{\partial \tau}$ since $p-\phi_{p}>0$. Overshifting in the ad valorem tax requires $\frac{d P}{d t}>P$, a necessary condition thus is that $\frac{\partial P}{\partial \tau}>1$. That is, overshifting in the unit tax is then a necessary, but not sufficient, condition for overshifting of the ad valorem tax.

- The coefficient for the relative effects on the demand is $\phi_{D}=(c+\tau) \lambda$. Using the price function in (11), $\left(p-\phi_{D}\right)$ turns out to be positive. But since $\frac{\partial D^{m}}{\partial \tau}<0$, we have $d D>0$.

- The coefficient for the profits is $\phi_{\pi}=P$, hence $d \pi=0$. Aggregates profits are then unaffected by the policy reform. However, it can be easily seen from (13) that the CSR part of the profits is only affected by $\lambda$ and is independent of $\tau$.

- Total CSR investment in (13) clearly decreases in $\lambda$ and is unaffected by the reduction in $\tau$ during the P-shift reform.

\section{Proof of Proposition 6}

Plugging the firm's optimal response to an ad valorem tax (Proposition 3) and the corresponding equilibrium values in (7), into the welfare function and maximizing with respect to $t$, the optimal tax rate obtains as in (10), which is a maximum since $\left.\frac{\partial^{2} W_{\text {sub }}}{\partial t}\right|_{t_{\text {sub }}^{*}}=-\frac{\left(2 c^{2}-\gamma \beta\right)^{4}}{2 \gamma\left(2 c^{2}+\gamma\right)^{3}}<0$. Observe that $t_{\text {sub }}^{*} \geq 0$ iff $\beta \leq \beta_{\text {inf }}$ or $\beta \geq \beta_{\text {sup }}$ where $\beta_{\text {inf }}=c-1$ and $\beta_{\text {sup }}=\frac{2 c^{2}}{\gamma}+c$, and $t_{\text {sub }}^{*}<0$ iff $\left.\beta \in\right] \beta_{\text {inf }}, \beta_{\text {sup }}$ [. Similarly, we obtain that $\tau_{\text {sub }}^{*}=0$ which is a maximum since $\frac{\partial^{2} W_{\text {sub }}}{\partial \tau}=-1 / \gamma$.

\section{Proof of Proposition 7}

- The optimal value of $\tau_{c \rho m p}$ is obtained from the first-order condition. It is a maximum so long as $\beta>\frac{3}{2}$ since $\frac{\partial^{2} W_{\text {comp }}}{\partial \tau^{2}}=-\frac{2 \beta-3}{\gamma}$. The optimal unit tax $\tau_{\text {comp }}^{*}>0$ iff

$$
\beta>\frac{2(\alpha-c)+\frac{\gamma}{2}}{\alpha-c+\frac{\gamma}{2}} \equiv \beta_{2}^{c r i t}
$$

Note that both $\frac{\partial \beta_{2}^{c r i t}}{\partial \gamma}$ and $\frac{\partial \beta_{2}^{c r i t}}{\partial(\alpha-c)}$ are strictly positive.

- The first order condition with respect to the ad valorem tax can be written as $\frac{d W_{\text {comp }}}{d t}=\frac{N(t)}{M(t)}$, where $M(t)=8 \gamma(1-t)^{4}$. Since $N(t)=0$ at the optimum, the second order condition can be written as $\frac{d W^{2}}{d^{2} t}=\frac{N_{t}(t)}{M(t)}<0$ which is a maximum whenever $N_{t}(t)<0$, that is, 


$$
t^{3}-3 t^{2}+3 t-1<a+b t
$$

where $a=\frac{-\gamma \beta(\beta+1)-\left(\alpha+\frac{\gamma}{2}\right)^{2}+\frac{\gamma}{2}}{2(\beta-1)\left[\gamma \beta^{2}+\left(\alpha+\frac{\gamma}{2}\right)^{2}\right]}$ and $b=\frac{\left(\alpha+\frac{\gamma}{2}\right)^{2}-c^{2}(\beta+1)+\gamma\left(\beta^{2}-1\right)}{2(\beta-1)\left[\gamma \beta^{2}+\left(\alpha+\frac{\gamma}{2}\right)^{2}\right]}$.

While the LHS of the above inequality is a strictly increasing cubic function in $t$ with $x$ and $y$-intercepts, respectively, $(1,0)$ and $(0,-1)$, the RHS is a linear function in $t$ with an $x$-intercept, $t_{0}$, that is strictly greater than unity for any positive value of $\beta$. To see this, observe that $t_{0}>1 \Longleftrightarrow-a>b$, this condition then rewrites $\beta>\frac{-\left(2 c^{2}+\gamma\right)}{2\left(c^{2}+\gamma\right)}$ which is always satisfied since the RHS is strictly negative. Thus, a sufficient condition for the inequality in (15) to hold, i.e. for the curve representing the LHS(t) be below that of the RHS(t) $\forall t \in[0,1]$, is that $b \leq 0$ that we solve to obtain the condition in the proposition.

\section{References}

Alves C, Santos-Pinto L (2008) A theory of corporate social responsibility in oligopolistic markets. Letöltve: http://citeseerx.ist.psu.edu/viewdoc/down-load

Andreoni J (1990) Impure altruism and donations to public goods: a theory of warm-glow giving. Econ J 100(401):464-477

Arora S, Gangopadhyay S (1995) Toward a theoretical model of voluntary overcompliance. J Econ Behav Org 28(3):289-309

Bagnoli M, Watts SG (2003) Selling to socially responsible consumers: competition and the private provision of public goods. J Econ Manag Strat 12(3):419-445

Banerjee S, Wathieu L (2017) Corporate social responsibility and product quality: complements or substitutes? Int J Res Market 34(3):734-745

Bansal S, Gangopadhyay S (2003) Tax/subsidy policies in the presence of environmentally aware consumers. J Environ Econ Manag 45(2):333-355

Bell DV (2002) The role of government in advancing corporate sustainability

Bénabou R, Tirole J (2010) Individual and corporate social responsibility. Economica 77(305):1-19

Bennett VM, Pierce L, Snyder JA, Toffel MW (2013) Customer-driven misconduct: how competition corrupts business practices. Manag Sci 59(8):1725-1742

Bernheim BD (1994) A theory of conformity. J Polit Econ 102(5):841-877

Besley T, Ghatak M (2007) Retailing public goods: the economics of corporate social responsibility. J Public Econ 91(9):1645-1663

Bovenberg AL, De Mooij RA (1994) Environmental levies and distortionary taxation. Am Econ Rev 84(4):1085-1089

Branco F, Villas-Boas JM (2015) Competitive vices. J Mark Res 52(6):801-816

Chiroleu-Assouline M, Fodha M (2014) From regressive pollution taxes to progressive environmental tax reforms. Eur Econ Rev 69:126-142

Conrad K (2005) Price competition and product differentiation when consumers care for the environment. Environ Res Econ 31(1):1-19

Cremer H, Thisse J-F (1994) Commodity taxation in a differentiated oligopoly. Int Econ Rev 613-633

Crifo P, Forget VD (2015) The economics of corporate social responsibility: a firm-level perspective survey. J Econ Surv 29(1):112-130

Croson R, Treich N (2014) Behavioral environmental economics: promises and challenges. Environ Res Econ 58(3):335-351

Dasgupta P, Southerton D, Ulph A, Ulph D (2016) Consumer behaviour with environmental and social externalities: implications for analysis and policy. Environ Res Econ 65(1):191-226

Daube M, Ulph D (2016) Moral behaviour, altruism and environmental policy. Environ Resour Econ 63(2):505-522

Delipalla S, Keen M (1992) The comparison between ad valorem and specific taxation under imperfect competition. J Public Econ 49(3):351-367

Delipalla S, O'Donnell O (2007) The comparison between ad valorem and specific taxation under imperfect competition: evidence from the European cigarette industry. University of Kent, School of Economics, Canterbury 
Diamond D (2009) The impact of government incentives for hybrid-electric vehicles: evidence from us states. Energy policy 37(3):972-983

Dröge S, Schröder PJ (2009) The welfare comparison of corrective ad valorem and unit taxes under monopolistic competition. Int Tax Public Finance 16(2):164-175

Ellingsen T, Johannesson M (2008) Pride and prejudice: the human side of incentive theory. Am Econ Rev 98(3):990-1008

European Commission (2001) Green paper: promoting a European framework for corporate social responsibility. Office for Official Publications of the European Communities

Fox T, Ward H, Howard B (2002) Public sector roles in strengthening corporate social responsibility: a baseline study. World Bank, Washington, DC

Freire-González J (2018) Environmental taxation and the double dividend hypothesis in cge modelling literature: a critical review. J Policy Model 40(1):194-223

Goulder LH (1995) Environmental taxation and the double dividend: a reader's guide. Int Tax Public Finance 2(2):157-183

John A, Pecchenino R, Schimmelpfennig D, Schreft S (1995) Short-lived agents and the long-lived environment. J Public Econ 58(1):127-141

Jørgensen JG, Schröder PJ (2005) Welfare-ranking ad valorem and specific tariffs under monopolistic competition. Canad J Econ/Revue canadienne d'économique 38(1):228-241

Kay JA, Keen MJ (1983) How should commodities be taxed?: Market structure, product heterogeneity and the optimal structure of commodity taxes. Eur Econ Rev 23(3):339-358

Kitzmueller M, Shimshack J (2012) Economic perspectives on corporate social responsibility. J Econ Lit 50(1):51-84

Manasakis C, Mitrokostas E, Petrakis E (2007) Corporate social responsibility in oligopolistic markets. University of Crete, Department of Economics

Mitrokostas E, Petrakis E (2007) Public policy and private CSR activities: complements or substitutes. CSR Paper, pp 22-2007

Moraga-Gonzalez JL, Padron-Fumero N (2002) Environmental policy in a green market. Environ Res Econ 22(3):419-447

Pearce D (1991) The role of carbon taxes in adjusting to global warming. Econ J 101(407):938-948

Suits DB, Musgrave RA (1953) Ad valorem and unit taxes compared. Q J Econ 67(4):598-604

Zhou Y (2018) The role of green customers under competition: a mixed blessing? J Clean Prod 170:857-866

Publisher's Note Springer Nature remains neutral with regard to jurisdictional claims in published maps and institutional affiliations. 